\title{
isoThiocyanates XXI. * (-)-10-Methylsulphinyldecyl isoThiocyanate, a New Mustard Oil Present as a Glucoside (Glucocamelinin) in Camelina Species
}

\author{
ANDERS KJER, ROLF GMELIN and ROALD BOE JENSEN
}

Chemical Laboratory of the University of Copenhagen, Denmark

\begin{abstract}
Seeds of the cruciferous species Camelina sativa (L.) Crantz, C. microcarpa Andrz. and C. dentata (Willd.) Pers. contain two isothiocyanate glucosides according to paperchromatographic analysis. The chief constituent, glucocamelinin, has been identified as a glucoside containing $(-) \cdot 10$-methylsulphinyldecyl isothiocyanate (VII) as the aglucone.

The new mustard oil is characterized as crystalline thiourea derivatives, formed by reaction with ammonia, aniline and benzylamine. The derivative with the last amine, (I), is degraded through well-defined steps to the compound (III), identical with a synthetic specimen of the previously unknown 1-benzyl-3-(10-methylthiodecyl)-urea. The mustard oil constitutes an addition to the class of naturally occurring sulphoxide-isothiocyanates discussed in a preceding communication of this series.
\end{abstract}

Tn the search for new naturally occurring isothiocyanates it was discovered Ithat seeds of the crucifer Camelina sativa (L.) Crantz contained two mustard oils, different from those previously recognized in Nature. Although C. sativa, indigenous to the Mediterranean region, has been cultivated as an oil-producing plant since ancient times, its contents of isothiocyanates do not appear to have been recognized previously.

In the present work paper chromatography of a seed extract of $C$. sativa, performed essentially as described by Schultz and Gmelin ${ }^{1}$, clearly disclosed the presence of two glucosides (Fig. 1). Schultz and Wagner ${ }^{2}$ recently introduced the symbol $R_{B}$, i.e. the ratio of the movement of the glucoside in question to that of a reference sample of glucotropaeolin, for paperchromatographic characterization of mustard oil glucosides. Adopting this convention we found the $R_{B}$-values 1.17 and 1.34 for the glucosides of $C$. sativa by descending chro-

* Part XX of this series: Acta Chem. Scand. 10 (1956) 1365.

Acta Chem. Scand. 10 (1956) No. 10 
Fig. 1. Descending paper chromatogram of isothiocyanate glucosides on Whatman paper No. 1. Solvent system: n-butanol:ethanol: water (4:1:4) . 1: Extract of seeds of Camelina sativa Crantz; 2: extract of seeds of Tropasolum majus $L$. A: Unidentified glucoside; $B$ : glucocamelinin; $C$ : glucotropaeolin.

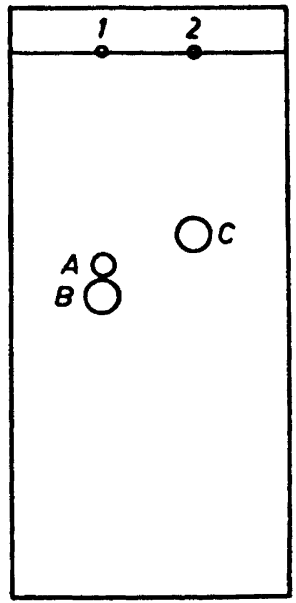

matography on Whatman paper No. 1 with the upper layer of the solvent system $n$-butanol:ethanol:water $(4: 1: 4)$ as the mobile phase. The glucoside possessing the highest $R_{B}$-value appeared to be the predominant constituent. Seed extracts of the closely related species $C$. microcarpa Andrz. and $C$. dentata (Willd.) Pers. showed the same paperchromatographic pattern. The two glucosides were selectively eluted from the proper regions of the paper and subjected to enzymic hydrolysis, followed by spectrophotometric investigation of the individual isothiocyanates. Both exhibited strong end-absorption in the short wave-length region in addition to a low-extinction shoulder at $c a$. 250-260 $\mathrm{m} \mu$, attributable to the isothiocyanate grouping. From previous results in this laboratory ${ }^{3}$ it appeared that the isothiocyanates were not of the volatile type.

When a larger seed sample was subjected to enzymic hydrolysis in the usual way, a crude levo-rotatory isothiocyanate fraction could be isolated by extraction with organic solvents. The product was transformed, without further purification, into crystalline, optically active thiourea derivatives by reaction with ammonia, aniline and benzylamine. After recrystallization, the derivatives were homogeneous as estimated from paper chromatography. Moreover, paperchromatographic comparison of the crude thiourea and an analytical specimen showed that the pure compounds were derivable from the isothiocyanate corresponding to the main glucoside. Analytical data clearly indicated the composition $\mathrm{C}_{12} \mathrm{H}_{23} \mathrm{ONS}_{2}$ for the parent mustard oil. Infra-red spectra left no doubt as to the presence of the side-chain sulphur atom in a sulphoxidegrouping, narrowing the above formula down to $\mathrm{C}_{11} \mathrm{H}_{23}(\mathrm{SO}) \mathrm{NCS}$. In order to elucidate the structure further, the benzylthiourea $(I)$ was transformed into the corresponding benzylurea (II) which, in turn, was reduced to the optically inactive sulphide-urea (III). Consequently, the sulphoxide-grouping represented the sole centre of asymmetry in the parent mustard oil. Raney-nickel hydrogenolysis of (III) furnished a sharp-melting, sulphur-free product which was not homogeneous, however, according to infra-red and analytical data. All 
attempts to fractionate the product failed but available data indicated that it consisted of ca. $25 \%$ of 1-cyclohexylmethyl-3-decyl-urea and about $75 \%$ of 1-benzyl-3-decyl-urea (IV). An authentic specimen of the latter was prepared from decylamine and benzyl isothiocyanate via the thiourea (V), and was found to melt $10^{\circ}$ higher than the hydrogenolysis product.

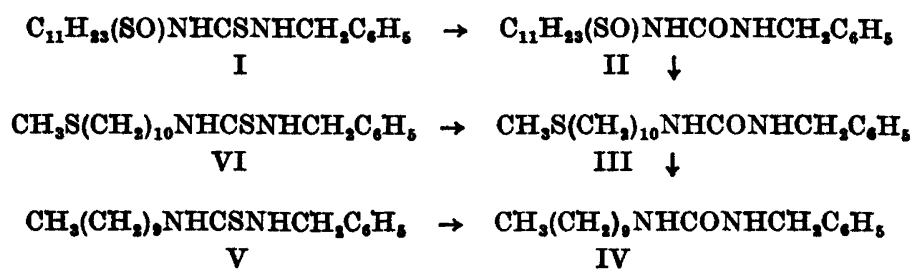

In order to establish the structure of (III) in an unambiguous way, a specimon of 1-benzyl-3-(10-methylthiodecyl)-urea was synthetized from the corresponding thiourea (VI) which, in turn, was produced from benzyl isothiocyanate and 10-methylthiodecylamine. Analyses, mixed melting point determination and infra-red spectra served to establish the identity of (III) as 1-benzyl-3(10-methylthiodecyl)-urea. Consequently, the Camelina mustard oil, whence it derives, is 10-methylsulphinyldecyl isothiocyanate (VII).<smiles>CCCCCCCCC(C)S(C)=O</smiles>

The mustard oil (VII) represents a novel addition to the class of naturally occurring, straight-chain $\omega$-methylsulphinylalkyl isothiocyanates. A previous paper of this series ${ }^{4}$ described the identification of (-)-5-methylsulphinylpentyl $i$ sothiocyanate (VIII), the aglucone of the natural glucoside glucoalyssin, and contained a discussion of various analogous substances and their configurational relationship.* The provenance and sign of rotation of (VII), as well as its thiourea derivatives, indicate that it belongs to the same configurational series as the formerly recognized species. Therefore, the new mustard

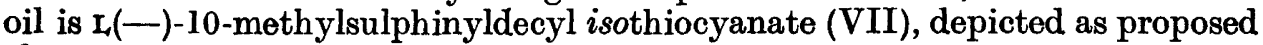
elsewhere ** (cf. Ref. $\left.{ }^{4}\right)$.

* Added in proof: After this paper has been submitted for publication we have identified (-)-9-methylsulphinylnonyl isothiocyanate as the mustard oil derivable from the natural glucoside glucoarabin $\%$

** Added in proof: By means of X-ray structural analysis Hine and Rogers ${ }^{10}$ have recently related the configuration at the $S$ atom of $(+)$-S-methyl-L-cysteine sulphoxide with that at the a-carbon atom, which is known, thus rendering the arbitrary proposal of Schmid and Karrer ${ }^{11}$ to use sulphoraphene as a configurational reference compound for sulphoxides superfluous. 
The progenitor of this compound is a glucoside for which we wish to propose the name glucocamelinin, in accord with general practice in this field. No efforts were made to isolate or characterize the glucoside, but its contents of sulphate and glucose were established by means of paper chromatography *. The nature of the minor glucoside in seeds of the Camelina species will be discussed in a forthcoming paper.

10-Methylthiodecylamine, required in the synthetic work, was prepared by Curtius degradation of 11-methylthioundecanohydrazide as described by Walker ${ }^{5}$. The latter compound was obtained by hydrazinolysis of the previously unknown methyl 11-methylthioundecanoate, easily prepared by photoinduced addition of methanethiol to methyl undecenoate in the presence of benzoyl peroxide and mercuric acetate. The addition reaction appears to be a more convenient route to the sulphide-ester than the previously employed fourstep reaction from the same starting material ${ }^{5}$.

\section{EXPERIMENTAL}

All melting points are uncorrected and determined in capillary tubes in a slowly heated bath.

Extraction and purification of glucocamelinin. Finely ground seeds of Camelina sativa Crantz $(200 \mathrm{~g})$ were defatted and extracted with hot $70 \%$ methanol. The solution was purified by lead salt as previously described for an analogous case 4. The buffered solution was subjected to enzymic hydrolysis and the liberated isothiocyanates taken up in chloroform. The extract was shaken briefly with a sodium bicarbonate solution in order to remove further impurities. The resulting crude, levo-rotatory mustard oil was divided into two halves and treated with ethanolic solutions of excess ammonia and aniline, respectively. Next day, the solvent was removed, and the crystalline derivatives purified by recrystallization from suitable solvents.

(-)-10-Methylsulphinyldecylthiourea. Three recrystallizations from ethyl acetate afforded the pure thiourea $(115 \mathrm{mg}$ ) as tiny, colourless prisms, m.p. 92-92.5 . (Found: C 51.60; $\mathrm{H} 9.23 ; \mathrm{N} 9.91 ; \mathrm{S} 22.95$. Calc. for $\mathrm{C}_{12} \mathrm{H}_{26} \mathrm{ON}_{2} \mathrm{~S}_{2}$ : C 51.75; $\mathrm{H} 9.41 ; \mathrm{N} 10.06 ; \mathrm{S} 23.03$ $[a]_{D}^{24}-65^{\circ} \pm 1.5^{\circ}(96 \%$ ethanol, $c=1.03)$. On paper chromatography in water-saturated chloroform by our usual method ${ }^{7}$, the new thiourea possessed the $R_{P h}$-value 1.15 . The ultra-violet spectrum in ethanol was of the usual type, $\lambda_{\max } 242 \mathrm{m \mu}(\varepsilon 13300)$ and $\lambda_{\min }$ $224 \mathrm{~m} \mu(\varepsilon 3240)$. Infra-red analysis of the solid thiourea in a potassium bromide disc

* Glucocamelinin appears to be of the usual glucoside structure type; available evidence in this laboratory, supplemented by the conclusive work by Ettlinger and Lundeen ${ }^{\circ}$ on the revised Gadamer-structure for the mustard oil glucosides, favour the expression:

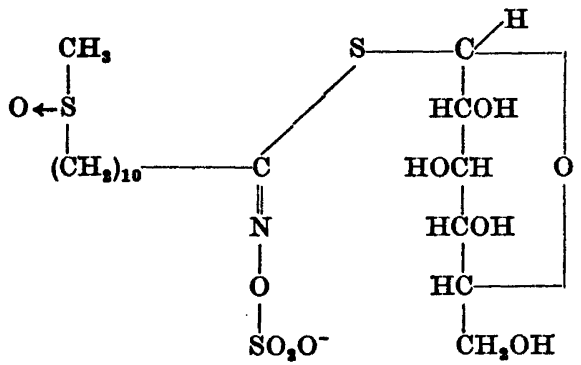

for the glucocamelinate ion, yet leaving the geometrical isomerism around the $C=N$ linkage undecided.

Acta Chem. Scand. 10 (1956) No. 10 
disclosed conspicuous bands at 2.91 (s)*, 3.30 (s), 6.10 (vs), 6.32 (vs), 6.93 (s), 7.32 (s), $8.59(\mathrm{w}), 9.83(\mathrm{vs}, \mathrm{S} \rightarrow 0$ ) and $13.60 \mu(\mathrm{m})$.

(-).1-(10-Methylsulphinyldecyl)-3-phenylthiourea. The reaction product of the now mustard oil and aniline separated from acetone as flat prisms, m.p. 139 ${ }^{\circ}$. (Found: C 60.90; $\mathrm{H} \mathrm{8.51;} \mathrm{N} 7.81 ; \mathrm{S} 18.10$. Calc. for $\mathrm{C}_{18} \mathrm{H}_{30} \mathrm{ON}_{2} \mathrm{~S}_{2}: \mathrm{C} 60.97 ; \mathrm{H} \mathrm{8.53;} \mathrm{N} \mathrm{7.90;} \mathrm{S} 18.08$ ). $[a]_{\mathrm{D}}^{24}-46^{\circ} \pm 1.5^{\circ}(96 \%$ ethanol, $c=0.43)$. The ultra-violet spectrum in ethanol exerted a maximum at $248 \mathrm{~m} \mu(\varepsilon 14600)$, a minimum at $228 \mathrm{~m} \mu(\varepsilon 9350)$ and a plateau at 255 $265 \mathrm{~m} \mu(\varepsilon 13950)$. In the infra-red spectrum a very strong band at $9.99 \mu$ was attributable to the sulphoxide grouping.

(-)-1-Benzyl-3-(10-methylsulphinyldecyl)-urea (II). The thiourea derivative, formed from the new mustard oil and benzylamine, separated from all solvents tested as a gelatinous product which was not brought to analytically pure condition. The benzylthiourea (I) $(618 \mathrm{mg}$ ) was desulphurized with silver nitrate $(573 \mathrm{mg})$ in dilute ethanol by heating on the steam bath for $10 \mathrm{~min}$. during which period $1 \mathrm{~N} \mathrm{NaOH}(3.4 \mathrm{ml})$ was gradually added in order to keep the reaction mixture near $\mathrm{pH} 7$. The calculated amount of silver sulphide was filtered off, and the filtrate concentrated to dryness in vacuo. The residue was repeatedly triturated with hot ethyl acetate from which the urea (II) separated in tiny, colourless needles on cooling (405 mg), m.p. $113-114^{\circ}$ (slight decomp.). (Found: C 64.60; $\mathrm{H} 9.09 ; \mathrm{N} 7.92 ; \mathrm{S} 9.27$. Calc. for $\mathrm{C}_{10} \mathrm{H}_{32} \mathrm{O}_{2} \mathrm{~N}_{2} \mathrm{~S}: \mathrm{C} 64.74 ; \mathrm{H} 9.15 ; \mathrm{N} 7.95$; S 9.10). $[a]_{\mathrm{D}}^{2 \mathrm{~A}}-53.6^{\circ} \pm 1.5^{\circ}(96 \%$ ethanol, $c=1.17)$.

1-Benzyl-3-(10-methylthiodecyl)-urea (III). The sulphoxide-urea (II) (288 mg) was dissolved in ethanol and treated with acid-activated zinc dust and a few drops of conc. $\mathrm{HCl}$ on the steam bath. After the rotation had decreased to practically zero, the solution was filtered hot and the filtrate evaporated to dryness. On digestion with water the solid urea $(264 \mathrm{mg}$ ) remained. It separated from aqueous ethanol in colourless platelets, m.p. 98.5-99.0 . (Found: C 67.70; $\mathrm{H} 9.42 ; \mathrm{N} \mathrm{8.21;} \mathrm{Calc.} \mathrm{for} \mathrm{C}_{10} \mathrm{H}_{82} \mathrm{ON}_{8} \mathrm{~S}: \mathrm{C} 67.83 ; \mathrm{H} \mathrm{9.59}$; N 8.33).

1-Benzyl-3-decyl-thiourea (V). This compound was easily obtained from $n$-decylamine and benzyl isothiocyanate as colourless, nacreous plates, m.p. 82.5 . (Found: C 70.50; $\mathrm{H} \mathrm{9.87;} \mathrm{N} \mathrm{9.06.} \mathrm{Calc.} \mathrm{for} \mathrm{C}_{18} \mathrm{H}_{30} \mathrm{~N}_{2} \mathrm{~S}: \mathrm{C} 70.53 ; \mathrm{H} \mathrm{9.87;} \mathrm{N} \mathrm{9.15)}$.

1-Benzyl-3-decyl-urea (IV). The thiourea (V) was desulphurized with silver nitrate, essentially as described above. The urea separated from $80 \%$ ethanol in thin, colourless needles, m.p. 97. (Found: $\mathrm{C}$ 74.60; $\mathrm{H}$ 10.47; $\mathrm{N}$ 9.69. Calc. for $\mathrm{C}_{18} \mathrm{H}_{30} \mathrm{ON}_{2}$ : $\mathrm{C}$ 74.43; $\mathrm{H} 10.41 ; \mathrm{N} 9.65)$.

Attempted hydrogenolysis of (III) with W-4 Raney nickel led to a sharply melting mixture (m.p. 87.5 ) of (IV) and the corresponding ring-hydrogenated product as estimated from analytical figures and from comparison of the infra-red spectrum of the mixture with that of pure (IV).

Methyl 11-methylthioundecanoate. A mixture of methyl undecenoate $(32.6 \mathrm{~g})$, benzoyl peroxide $(80 \mathrm{mg})$ and mercuric acetate $(150 \mathrm{mg})$ was placed together with methanol $(50 \mathrm{ml})$ and methanethiol $(7.91 \mathrm{~g})$ in a water-cooled quartz flask, which was exposed to ultraviolet irradiation from a quartz-mercury lamp for 7 hours. Next day, a slight precipitate was filtered off, and methanol was removed from the filtrate by distillation. Pure methyl 11-methylthioundecanoate $(31.7 \mathrm{~g}, 80 \%)$ distilled as a colourless oil, b.p. $119^{\circ} / 0.1$ $\mathrm{mm} ; n_{\mathrm{D}}^{25}$ 1.4651. (Found: $\mathrm{C} 63.50 ; \mathrm{H}$ 10.72; $\mathrm{S}$ 12.80. Calc. for $\mathrm{C}_{13} \mathrm{H}_{26} \mathrm{O}_{2} \mathrm{~S}: \mathrm{C} 63.37 ; \mathrm{H} \mathrm{10.64}$; S 13.02).

Hydrolysis of the ester with ethanolic $\mathrm{KOH}$ afforded 11-methylthioundecanoic acid, separating from aqueous ethanol in colourless, nacreous plates, m.p. $44^{\circ}$ (Ref. ${ }^{8}$ m.p. $\left.43-45^{\circ}\right)$.

10-Methylthiodecylamine. The above methyl ester was transformed into the corresponding hydrazide as described elsewhere ${ }^{5}$. The pure hydrazide, separating from aqueous ethanol as flat prisms, was found to melt at 92.0-92.5 (Ref. 5 m.p. 88-89'). (Found: C 58.70; $\mathrm{H}$ 10.58; $\mathrm{N}$ 11.38. Calc. for $\mathrm{C}_{12} \mathrm{H}_{26} \mathrm{ON}_{2} \mathrm{~S}$ : $\mathrm{C} 58.49 ; \mathrm{H} 10.64 ; \mathrm{N} 11.37$ ).

The Curtius degradation of the hydrazide was performed as described by Walker ${ }^{5}$, yet in somewhat lower yield. The amine distilled as a viscous, colourless oil at $165^{\circ} / 15 \mathrm{~mm}$. The hydrochloride was prepared, m.p. $161-162^{\circ}$ (Ref. ${ }^{5}$ m.p. $160-161^{\circ}$ ).

\footnotetext{
* $\mathrm{vs}=$ very strong; $s=$ strong; $m=$ medium and $w=$ weak.
} 
1-Benzyl-3-(10-methylthiodecyl)-thiourea (VI). The reaction between 10-methylthiodecylamine and benzyl isothiocyanate proceeded smoothly to give a quantitative yield of the thiourea (VI). This separated from $70 \%$ ethanol in colourless, shiny platelets, m.p. 73 ${ }^{\circ}$. (Found: $\mathrm{C} 65.10 ; \mathrm{H} \mathrm{9.06;} \mathrm{N} \mathrm{8.00.} \mathrm{Calc.} \mathrm{for} \mathrm{C}_{18} \mathrm{H}_{32} \mathrm{~N}_{2} \mathrm{~S}_{2}: \mathrm{C} 64.73 ; \mathrm{H} \mathrm{9.15}$; $\mathrm{N} 7.95$ ).

Desulphurization of (VI) to (III). When the thiourea was subjected to desulphurization with silver nitrate, essentially as described above, 1-benzyl-3-(10-methylthiodecyl)urea (III) was obtained in $84 \%$ yield, m.p. $100^{\circ}$, undepressed on admixture with the above specimen, prepared by degradation of the natural derivative. The identity of the two preparations was further substantiated by their coinciding infra-red spectra.

Microanalyses were performed in this laboratory by Mr. P. Hansen. We wish to thank the Department of Plant Culture of the Royal Danish Veterinary and Agricultural College for the gift of a substantial sample of Camelina seeds.

This work is part of investigations supported by Statens Almindelige Videnskabsfond (The Danish State Research Foundation) and Carlsbergfondet (Thie Carlsberg Foundation).

\section{REFERENCES}

1. Schultz, O.-E. and Gmelin, R. Z. Naturforsch. 8b (1953) 151.

2. Schultz, O.-E. and Wagner, W. Z. Naturforsch. 11 b (1956) 73.

3. Kjær, A., Conti, J. and Larsen, I. Acta Chem. Scand. 7 (1953) 1276.

4. Kj:er, A. and Gmelin, R. Acta Chem. Scand. 10 (1956) 1100.

5. Walker, J. J. Chem. Soc. 1950193.

6. Ettlinger, M. G. and Lundeen, A. J. J. Am. Chem. Soc. 78 (1956) 4172.

7. Kjær, A. and Rubinstein, K. Acta Chem. Scand. 7 (1953) 528.

8. Rapoport, L., Smith, A. and Newman, M. S. J. Am. Chem. Soc. 69 (1947) 693.

9. Kjær, A. and Gmelin, R. Acta Chem. Scand. 10 (1956) 1358.

10. Hine, R. and Rogers, D. Chemistry \& Industry 19561428.

11. Schmid, H. and Karrer, P. Helv. Chim. Acta 31 (1948) 1497.

Received August 29, 1956. 